\title{
MICROSTRUCTURE AND PHASE-TRANSFORMATION IN MELTSPUN SHAPE MEMORY ALLOYS
}

\author{
P. DONNER \\ Ruhr-Universität Bochum, Institut für Werkstoffe, Postfach 1021 48, D-4630 Bochum, Germany
}

\begin{abstract}
The rapid solidification at the meltspinning process causes a microcrystalline structure in the ribbon-shaped semifinished products, in which the microstructure is strongly affected by the cooling-rate. Hence follows a homogeneous microstructure for copper-based alloys in every cooling-condition and a micro-segregated dendritic structure at low and intermediate cooling-rates for the Fe-Mn-based specimen.

Differential scanning-calorimetry and electrical resistance provide data on the starting temperatures and the course of martensitic transformation in as-quenched and recrystallized ribbons. The incomplete martensitic transformation of the Fe- $\mathrm{Mn}$-based specimens is observed by X-Ray measurements.

The mechanical properties and the shape memory effect of the ribbons are compared to those of the conventionally produced material. Furthermore the effect of heat-treatments in copper-based ribbons will be described.
\end{abstract}

\section{Introduction}

Since conventional melting and subsequent plastic deformation of shape memory alloys requires an extensive effort, the production of thin ribbons directly from the liquid by meltspinning may be of advantage from the technical point of view.

Rapid quenching enables the formation of homogeneous microstructures without any heat-treatment in most cases, since high rates of cooling support massive crystallization, which leads to homogeneous distribution of solution. In addition a favourable microstructure with columnar grains and solidification texture can be achieved by meltspinning, as shown in earlier experiments with $\mathrm{Cu}$-based shape memory alloys $[1,2]$.

With regard to the Fe-Mn-based shape memory alloys, meltspinning can offer a favourable method of manufacture, too, because these alloys indicate the highest amount of reversibility in thin sheets or wires $[3,4]$.

The present paper aims at the comparison of meltspun $\mathrm{Fe}-\mathrm{Mn}$ - and $\mathrm{Cu}$-based shape memory alloys. At first, the microstructures resulting from meltspinning at variable wheel-velocities and their influences on the martensitic transformation behaviour are shown.

Besides the investigations on mechanical and shape memory properties, the effect of different heat-treatments on microstructure and the course of transformation in $\mathrm{Cu}-\mathrm{Al}-\mathrm{Ni}$-ribbons will be reported.

\section{Experimental Procedures}

For the meltspinning-process quantities of $7-10 \mathrm{~g}$ of the alloys were molten in quartz crucibles with nozzle diameters from 0.8 up to $1.4 \mathrm{~mm}$. The molten alloys were spun with argon ejection pressures of 0.7 up to 1 bar onto a rotating copper-wheel with a diameter of $200 \mathrm{~mm}$, using wheel velocities in the range from 5 up to $50 \mathrm{~m} / \mathrm{s}$. The spinning equipment was placed in a vacuum 
chamber under a helium atmosphere of 0.6 bar. The ribbon thickness was deternimed micrometrically.

The microstructures were observed by light microscopy, SEM and TEM. The phase-transformation-temperatures were measured by DSC (DuPont TA 2100) or electrical resistance. The amount of residual austenite in the martensitic state $(\mathrm{Fe}-\mathrm{Mn}-\mathrm{Si})$ was determined by $\mathrm{X}$-ray diffractometry $(\mathrm{Mo}-\mathrm{K} \alpha)$.

All tensile test specimen had the same defined $\mathrm{L}_{0}$ of $10 \mathrm{~mm}$, the edges of the specimens were grinded to reduce fatigue notch. The amount of reversible strain under constant load was measured by applying tensile load parallel to the ribbon-axis, where the specimens were positioned in an induction furnace with integrated cooling-pipes to enable thermal cycling in a temperature range from $-100^{\circ} \mathrm{C}$ up to $350^{\circ} \mathrm{C}$.

\section{Results and Discussion}

\section{$-\mathrm{Fe}-\mathrm{Mn}-\mathrm{Si}-\mathrm{rib}$ bons}

In these alloys the shape memory effect is promoted on the one hand by a simple lattice-changing shear mechanism and on the other hand by a very small change of volume ( $\leq 2 \%)$. During transformation of the fcc $\gamma$-high-temperature phase into the hcp $\epsilon$-low-temperature phase, there is a change in the stacking sequence from $A B C A B C$ to $A B A B .$. The movement of interfaces between the two phases, needed for the change of stacking sequence, is made possible by the formation of partial dislocations. These simple crystallographic shear mechanism should be a good prerequisite for thermoelastic properties; yet the transformation in this alloy is influenced by some parameters, which act against a plain thermoelastic transformation. A nearly complete shape memory effect has been found in alloys containing a suitable amount of $\mathrm{Mn}(28-32 \mathrm{wt} \%)$ and $\mathrm{Si}(5-6 \%)$ by which the volume fraction of transformed $\epsilon$-martensite and the position of $\mathrm{T}_{\mathrm{N}}$ (transformation para- to antiferromagnetic) are determined, the most important parameters with respect to the maximum value of reversible shape change. Besides these, specimen-thickness and thermomechanical treatment also have a significant influence on the effect [5-7].

Since experiments with meltspun Fe-Mn-based shape memory alloys have indicated that in these thin ribbons a good one-way-effect is practicable, further experiments at different wheel-velocities had been done with a Fe-30Mn-5Si-alloy. The aim was to take an influence on the phasetransformation-temperatures $(\rightarrow$ improvement of the SME) and the mechanical properties $(\rightarrow$ improvement of work capacity) without any thermomechanical treatment.

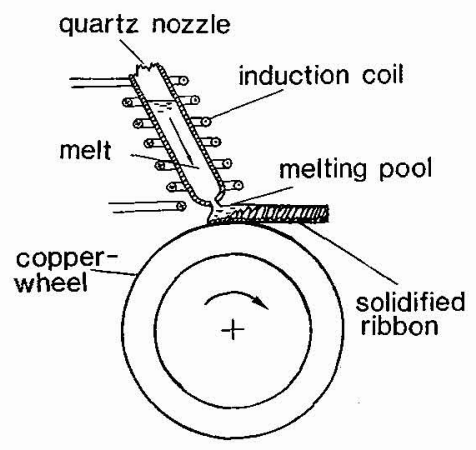

cooling-rate $\dot{T}$

free surface
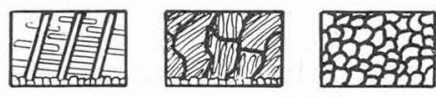

contact side

dendritic structure

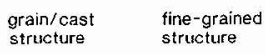

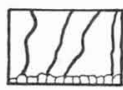
columnar
structure

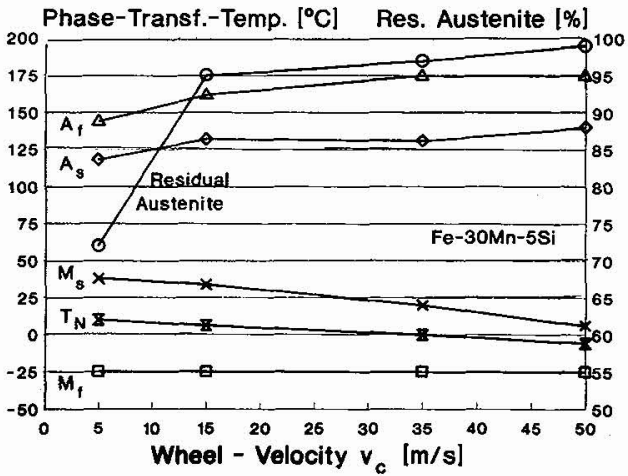

Fig. 2: Phase-Transformation-Temperatures and amount of residual austenite in $\mathrm{Fe}-30 \mathrm{Mn}-$ $5 \mathrm{Si}$ in dependence of the chosen wheel velocity

Fig. 1: Schematic characterization of the meltspinning technique and the microstructures which can be obtained 
Fig: 1 shows a schematic characterization of the meltspinning procedure and the resulting microstructures for SMA in dependence of the cooling-rate, which is directly influenced by the chosen wheel-velocity. In the case of $\mathrm{Fe}-30 \mathrm{Mn}-5 \mathrm{Si}$, the whole range of phenomena between coarse dendrites and homogeneous grains can be obtained. Dendritic growth disappears at wheel-velocities higher than $30 \mathrm{~m} / \mathrm{s}$. There is no significant influence of the dendritic structure on the transformation behaviour, a more detailed discussion is given in [4].

Fig. 2 indicates a slight change in the phase-transformation-temperatures in dependence of increasing wheel-velocity. While $M_{f}$ remains constant, $M_{s}$ is lowered for $30^{\circ} \mathrm{C}$ at the highest cooling-rate $\left(v_{u}=50 \mathrm{~m} / \mathrm{s}\right)$. Since $A_{s}$ and $A_{f}$ increase up to $25^{\circ} \mathrm{C}$, the hysteresis gets larger by meltspinning at higher wheel-velocities. The amount of residual austenite which comes generally up to more than $50 \%$ in $\mathrm{Fe}-\mathrm{Mn}$-based alloys, is influenced in the same manner. The meltspun ribbons exhibit values up to $97 \%$ at maximum $\mathrm{v}_{\mathrm{u}}$, thereby the original state of the bulk material amounts $65 \%$. Besides $\mathrm{M}_{\mathrm{s}}$ and residual austenite the magnetic ordering, due to the transition paramagnetic to antiferromagnetic at the Nèl-Temperature $\left(\mathrm{T}_{\mathrm{N}}\right)$, is a variable parameter, too. Similar to $\mathrm{M}_{\mathrm{s}}$, a decrease of $\mathrm{T}_{\mathrm{N}}$ can be observed, with simultaneously approach to each other. This causes a superposition of the magnetic and martensitic transformation, which becomes obvious in the electrical resistance curve. Since magnetic ordering leads to a stabilization of austenite, this matter of fact seems to be responsible for an observed decrease of the reversible shape change in dependence of spinning-velocity. Indeed the maximum reversible strain amounts only $\approx 1 \%$ under constant load in tensile direction for bulk- and $5 \mathrm{~m} / \mathrm{s}$-specimen [8], but this value is still lowered down to $0.35 \%$ in specimens meltspun at higher velocities. The residual austenite, which is indicated by the small volume fraction of transformable $\epsilon$-martensite, is on the one hand a result of magnetic ordering, on the other hand it is directly influenced by high rates of internal stresses and defect density, frozen in by rapid quenching from the melt, i.e. this effects are the main causes for the change in $\mathrm{M}_{\mathrm{s}}$ and $\mathrm{T}_{\mathrm{N}}$.

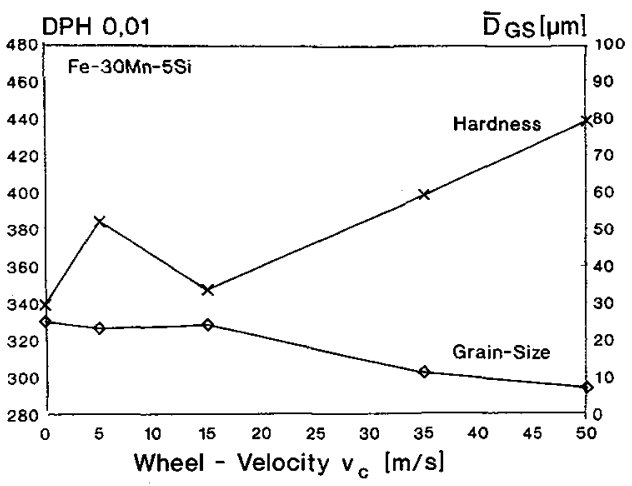

Fig. 3: Hardness and grain size in dependence of wheel velocity ( 0 signifies bulk material)

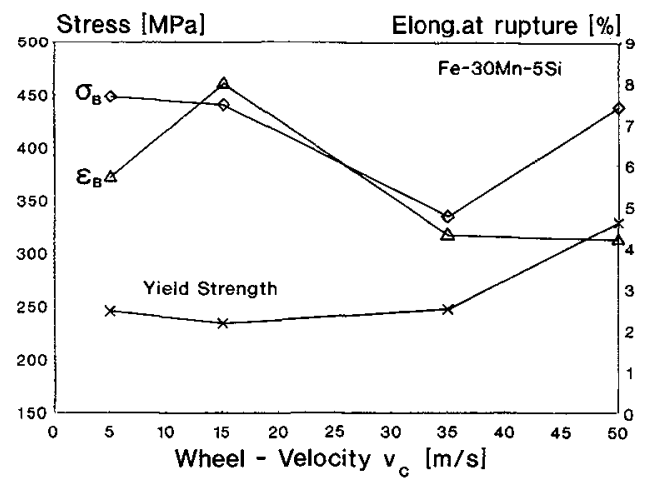

Fig. 4: Mechanical properties (tensile test) of meltspun ribbons (mean values of 7 measurements)

Not only the transformation-behaviour and consequently the shape memory effect, but the mechanical properties are affected by this internal stresses and defects. This is indicated by the observed increase in hardness without a significant change in the grain-size (Fig. 3) and the higher yield strengths, which are obtained at higher cooling-rates (Fig. 4). The values of $\sigma_{\mathrm{B}}$ and $\epsilon_{\mathrm{B}}$ have to be interpreted with respect to a deterioration of ribbon-quality (holes, notches) by increasing wheel-velocity.

Due to the results it becomes evident that meltspinning at higher velocities than $5 \mathrm{~m} / \mathrm{s}$ does not lead to an improvement in shape memory, although a strengthening of the material can be achieved. Obviously microstructure and ordering mechanisms are the dominant parameters with respect to transformation-behaviour in meltspun $\mathrm{Fe}-\mathrm{Mn}-\mathrm{Si}-\mathrm{rib}$ bons. 
$-\mathrm{Cu}-\mathrm{Al}-\mathrm{Ni}-\mathrm{ribbons}$

$\mathrm{Cu}-\mathrm{Al}-\mathrm{Ni}$-shape memory alloys belong to the group of $\beta$-Hume-Rothery-phases characterized by a 3:2 e/a-ratio. The high-temperature $\beta$-phase is bcc, having an ordered $\mathrm{DO}_{3}$ superlattice, which transforms to close-packed layer structures (fcc or hcp) at $\mathbf{M}_{\mathbf{s}}$. Contrary to Fe-Mn-Si, this type of martensitic transformation performs all prerequisites for thermoelasticity. Nevertheless, high brittleness and instability of the effect by using the alloys at elevated temperatures limit the application of $\mathrm{Cu}-\mathrm{Al}-\mathrm{Ni}$.

Since meltspun $\mathrm{Cu}-\mathrm{Al}-\mathrm{Ni}-$ ribbons with columnar structure are able to show a $\langle 100\rangle$ fibre texture, which favours large transformation induced strains [2], the influence of rapid quenching and subsequent heat-treatments on $\mathrm{Cu}-12.7 \mathrm{Al}-4.11 \mathrm{Ni}-$ alloy $\left(\mathrm{M}_{\mathrm{S}} \approx 180^{\circ} \mathrm{C}\right)$ was investigated with the aim to improve its properties with respect to shape memory.

Independent from the chosen wheel-velocity, a homogeneous microstructure is always obtained in the specimens. Fig. 5 illustrates that the grain size shows a scale of a tenth after meltspinning, thereby additionally rebetatization-treatments of the as-quenched states $\left(900^{\circ} \mathrm{C}, 30 \mathrm{~min}\right.$ for all spinning-velocities) lead to grain-sizes around $40 \mu \mathrm{m}$, corresponding to those of the ribbons meltspun at $\mathrm{v}_{\dot{u}}=5 \mathrm{~m} / \mathrm{s}$. Similar to the $\mathrm{Fe}-\mathrm{Mn}-\mathrm{Si}-\mathrm{ribbons}$, the transformation-hysteresis becomes greater with increasing cooling-rate (Fig. 6). The fact that the hysteresis of rebetatized ribbons remains constant on a level of $15^{\circ} \mathrm{C}$ (value of the bulk material) for the different spinning-velocities corroberates the influence of internal stresses and defects on the transformation-behaviour. This is also effective with respect to the mechanical properties. Fig. 5 demonstrates the superposition of fine-grain-hardening, which causes the difference in hardness between bulk material and ribbons meltspun at low wheel-velocities $(5+15 \mathrm{~m} / \mathrm{s})$, with the strengthening effect of the internal stresses and defects at higher speeds (hardness of all rebetatized specimen: 295 DPH 0,01 ).

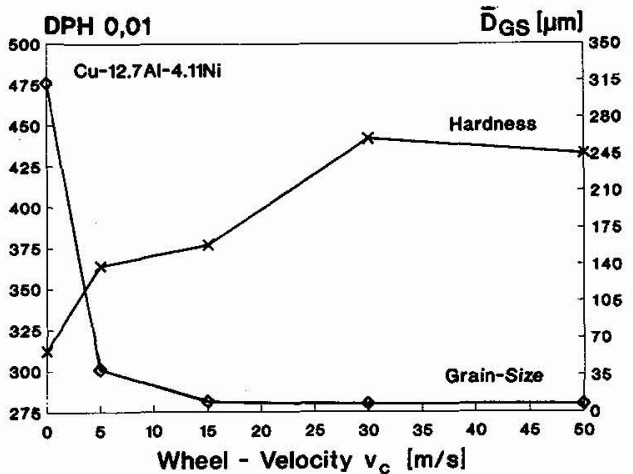

Fig. 5: Hardness and grain size of $\mathrm{Cu}-12.7 \mathrm{Al}-4.11 \mathrm{Ni}$ in dependence of wheel velocity

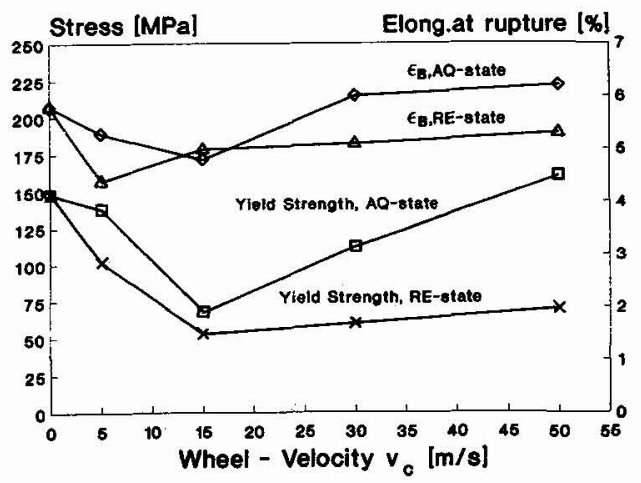

Fig. 7: Mechanical properties of meltspun ribbons in the as quenched and rebetatized state (mean values of 7 measurements)

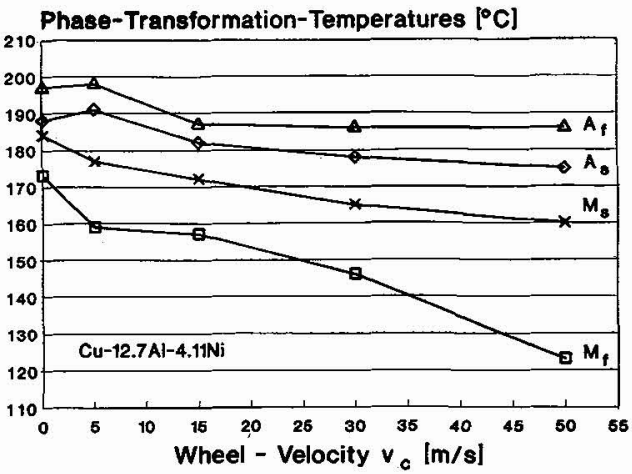

Fig. 6: Phase-transformation-temperatures after meltspinning at different wheel velocities

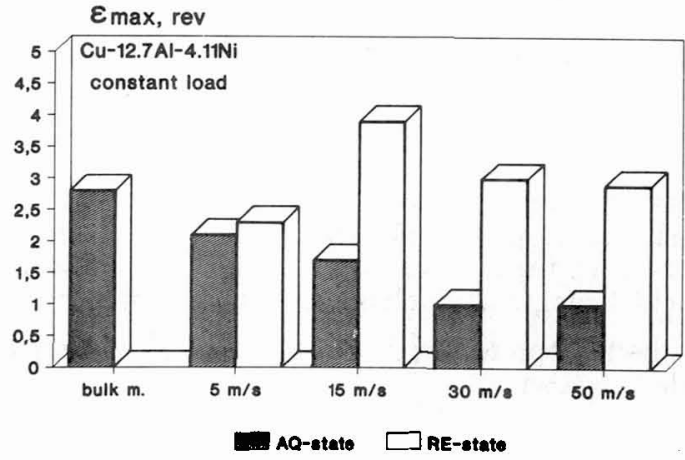

Fig. 8: Maximum reversible transformation strain under constant load in different specimens 
Since the ribbon-quality becomes worse with rising velocity, e.g. holes and notches caused by turbulences and crumbling of the ribbons in the collecting hopper of the equiprnent, the results of the tensile tests, indicated in Fig. 7, should not be reviewed to their absolute values. In relation to each other, the ribbons show an increase in yield strength at higher spinning-velocities (AQstate), in contrast to the rehomogenized state (RE-state). Besides, an intergranular fracturebehaviour, caused by a high oxygen-content at the grain-boundaries after the heat-treatment, can be observed in the RE-state. Because no crack arrest mechanism takes place in this coarsegrained, columnar structure, a lower stress level and early fracture is obtained.

In spite of this fact, the complete columnar structure obtained by rebetatization favours the reversible shape change in the ribbons. For the RE-state an improvement of the one-way-effect under constant load conditions can be observed opposite to bulk specimens and ribbons in the AQ-state (Fig. 8). Beyond, a more extensive improvement should be possible considering the unfavourable ribbon-quality. The schematic conception in Fig. 9 characterizes the advantage of columnar microstructures with fibre texture. Since a single crystal with [100]-orientation represents the ideal condition for the martensitic transformation within the shear-system (100) [110], a complete columnar structure with [100]-fibre texture can exhibit a greater shearangle $\gamma$ - and consequently a higher amount of reversible shape change - like polycrystals with random orientation.

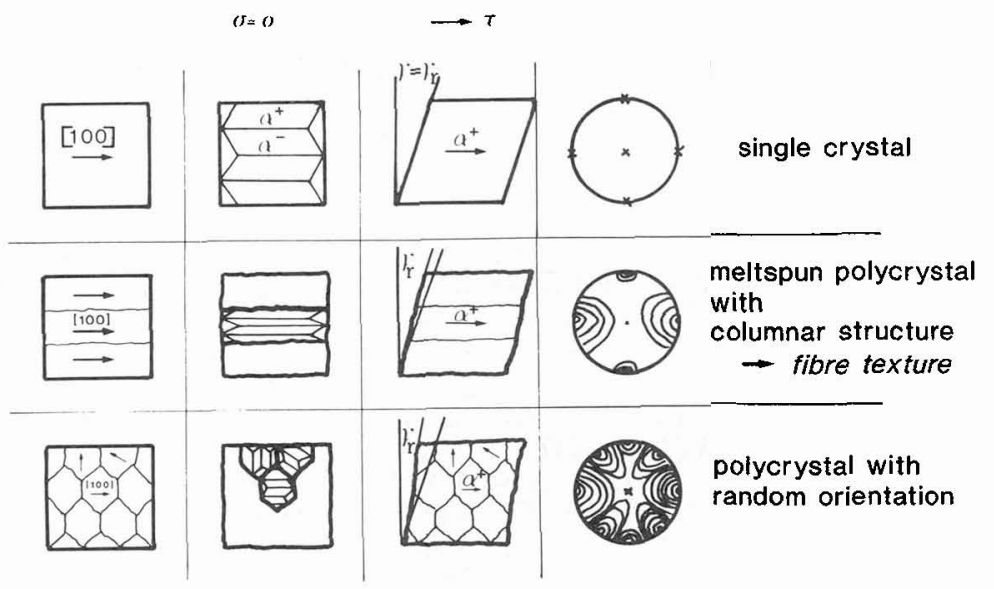

Fig. 9: Dependence of the maximum reversible transformation strain on microstructure and crystallographic orientation, schematically

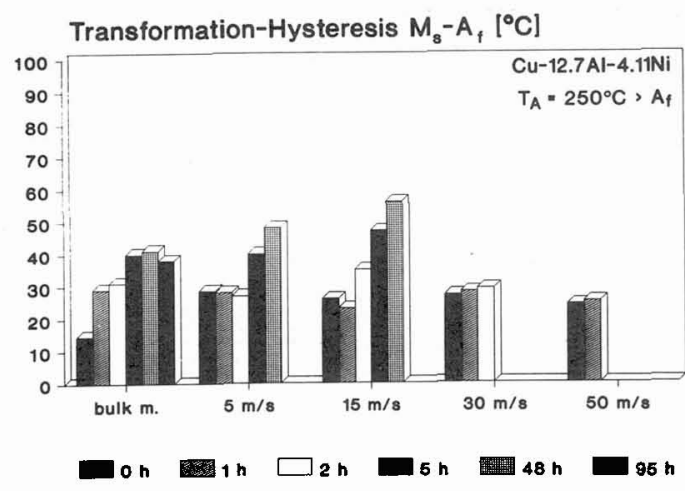

Fig. 10a: Change in transformation hysteresis after $\beta$-phase ageing $\left(250{ }^{\circ} \mathrm{C}\right)$ for different times $\rightarrow \mathrm{AQ}-$ state

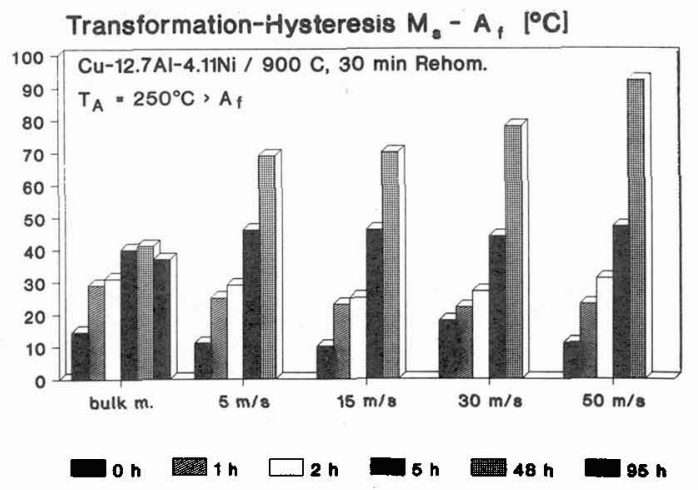

Fig. 10b: Change in transformation hysteresis after $\beta$-phase ageing $\left(250^{\circ} \mathrm{C}\right)$ for different times $\rightarrow \mathrm{RE}$-state 
Furthermore, a rehomogenization-treatment of the ribbons can support a better stability of the transformation-behaviour at elevated temperatures. Fig. $10 \mathrm{a}+\mathrm{b}$ shows a comparison of the transformation-hysteresis in $\mathrm{AQ}$ - and $\mathrm{RE}$-specimens after ageing in the austenitic state $(\mathrm{Ta}=250$ $\left.{ }^{\circ} \mathrm{C}\right)$. Generally, an increase of the hysteresis $\left(M_{s}-A_{f}\right)$ can be observed, due to the following facts : $\mathrm{U}_{\mathrm{p}}$ to an ageing-time of $5 \mathrm{~h}$ (maximum of the curve) the phase transformation temperatures are rising in all specimens, thereby $A_{S}$ and $A_{f}$ are more shifted than the Martensitefemperatures. To longer times all temperatures decrease except $A_{f}$, which is lowered in the bulk material, but remains nearly constant at the maximum value for the $A Q-$ and $R E-s t a t e s, i . e$. the hysteresis of the meltspun ribbons is more significantly changed than that of the bulk material. This is also illustrated by the fact that the transformation temperatures of the AQ-states meltspun at higher velocities could not be determined, because no transformation-peak was detectable by DSC.

The changes in hysteresis can be explained by a superposition of several effects. In the first stage of ageing the annihilation of defects and internal stresses leads to an increase of $\mathbf{M}_{\mathbf{s}}$ (necessary undercooling $\Delta \mathrm{T} \downarrow)$, while simultaneously ordering mechanisms $\left(\mathrm{DO}_{3}\right.$-structure) take an influence on $\mathrm{T}_{0}$. In the second stage precipitation processes [9] - indicated in this investigations by an increase in hardness and changes in alloy-content - mainly affect the transformation. With an increasing amount of precipitates the volume fraction of transformable martensite gets smaller and the reverse transformation is impeded $\left(A_{f} \uparrow\right)$. In this specimens the transformation-peaks are flat and broadened with a significant reduce of the transformation-enthalpy $\Delta h$. In the finer grained microstructures of the AQ-state the precipitates completely inhibit the transformation, whereas the columnar structure obtained by grain-growth supports further transformation, which is nevertheless limited by the ribbon-thickness.

\section{References}

11. DONNER, P. and EUCKEN, S., Mat. Sc. Forum Vol. 56-58 (1990) 723 (ICOMAT 89)

2. EUCKEN, S., HIRSCH, J. and HORNBOGEN, E., Textures and Microstructures, 889 (1988) 415

[3] EUROPEAN PATENT OFFICE: 0176272A1, Shape Memory Alloy and Method for Producing the Same

[4] DONNER, P., SADE, M. and HORNBOGEN, E., J. Mat. Sci. Let. 8 (1989) 37

$5 . \quad$ SEEGER, A., Z. Metallkde. 44 (1953) 247

6. SATO, A., YAMAJI, Y. and MORI, T., Acta Metall. 34, No. 2 (1986) 287

7 ROBINSON, J. S. and McCORMICK, P. G., Mat. Sc. Forum Vol.-56-58 (1990) 649

[8] DONNER, P. and HORNBOGEN, E., The Martensitic Transformation in Science and Technology, E. Hornbogen, N. Jost (eds), DGM-Informationsgesellschaft Oberursel (1989), 267

[9] KUWANo, N. and WAYMAN, C. M., Met. Trans. A. Vol.15 (1984) 621

\section{Acknowledgements}

Financial support of the German Ministry of Science and Technology (BMFT 03M5006B5) and the German Science Foundation (DFG Ho 325/21-3) is gratefully acknowledged.

Special thanks are due to Dr. Marcos Sade (Centro Atomico Bariloche) for his kind help in electrical resistance measurements.

The $\mathrm{Cu}-\mathrm{Al}-\mathrm{Ni}$ pre-alloy was industrially prepared by TREFIMETAUX, Serifontaine, France. 